\title{
A Conceptual Model for G2G Relationships
}

\author{
Heni Hamza, Mellouli Sehl, Karuranga Egide, and Poulin Diane \\ Faculty of Business Administration, Laval University \\ Québec, G1V0A6, Canada \\ hamza.heni.1@ulaval.ca, \\ \{sehl.mellouli, egide.karuranga, diane.poulin\}@fsa.ulaval.ca
}

\begin{abstract}
This paper proposes a conceptual model that groups different factors that can influence relationships between government agencies. The model is based on a systematic literature review of published papers related to Government-to-Government (G2G) relationships. Through analysis of selected papers, we identified, classified, and organized factors that may impact relationships between government agencies. The proposed model may help government managers to improve their G2G policies.
\end{abstract}

Keywords: E-Government, G2G, Governance, Conceptual model.

\section{Introduction}

One objective of e-government is to provide a single entry point for all government services to citizens. Generally, these services are organized as life-events [10. For example, in the province of Quebec, Canada, becoming a father requires 25 services in 15 government agencies whereas moving from one place to another requires 16 services in 13 different government agencies [15. The success of a single entry point will depend on service quality.

E-government has gone through four phases: the information phase, the interaction phase, the transaction phase, and the integration phase [4. The integration phase is more than the government having a web presence. In fact, government agencies collaborate with each other to provide this service, to share information, and to integrate their processes. Hence, several government agencies can be involved in delivering each service at a single entry point. Consequently, e-government success depends on relationships between the different government agencies that have to coordinate their activities to serve citizens better. These relationships are referred to as Government-to-Government (G2G).

Government-to-Government (G2G) is a relationship between two government agencies. A successful G2G has the necessary resources for collaboration and communication between government agencies with the aim of better serving citizens. Hence, G2G improves and builds up cooperation and collaboration between government agencies. Communication between government agencies, i.e., exchange of data, depends on the collaboration and cooperation mechanisms that they put in place. 
This partnership cannot be established without developing a governance relationship between government agencies [16]. Consequently, it may be important to develop many strategies as well as policies for inter-agency coordination and collaboration for the implementation of G2G. To create and implement such a one-stop single-entry point, it is first necessary to eliminate hierarchies and remove physical barriers between the different government agencies.

The objective of this paper is to identify, organize, and classify the different factors that influence governance relationships between government agencies. To this end, we propose a conceptual model of factors and dimensions, using inductive qualitative analysis of scientific papers selected through a systematic literature review. This model is part of a research project on the relationships between the central Quebec government and its regional government agencies. The objective is to see how regional government agencies can inform the central government about the specific needs of citizens, and how the services are made available online to citizens.

This paper is organized as follows. Section 2 presents the systematic literature review on G2G. Section 3 presents a review of selected G2G studies. Section 4 details the proposed conceptual model of factors. Finally, section 5 is the conclusion.

\section{Literature Review Methodology}

We adopted a systematic literature review approach. Such an approach provides a rigorous, reproducible, transparent, and scientific process for selecting and filtering scientific papers [5. It also helps to reduce errors, strengthen legitimacy, and improve result reliability 3 .

The literature review was performed (see Figure 1) on the various studies to identify the factors that affect relationships between government agencies. There were three stages. The first stage was to determine which databases would be searched. The chosen databases were 1) Proquest, 2) EBSCO, 3) ISI Web of Science, 4) ScienceDirect, 5) Social Science, and 6) GPO Access.

The second stage defined a list of key words for the search. The key words were: G2G, e-government, online government, online service, municipalities, agencies, ministries, administrations, local governments, public agencies, cities, regions, public relations, governance, technology, collaboration, communication, sharing, factor, challenge, acceptance, reluctance, manager. To improve the search, we associated each key word with a thesaurus. Figure 2 illustrates the thesaurus for the key word government. The thesauri were generated using the tool provided by the web site www.visaulthesaurus.com. A thesaurus provides the terms of a specific domain using semantic relationships (synonyms, antonyms, homonyms, relationships, etc.). Figure 3 gives examples of our search queries. The queries were based on the entire thesaurus, and applied to abstracts or full texts. 


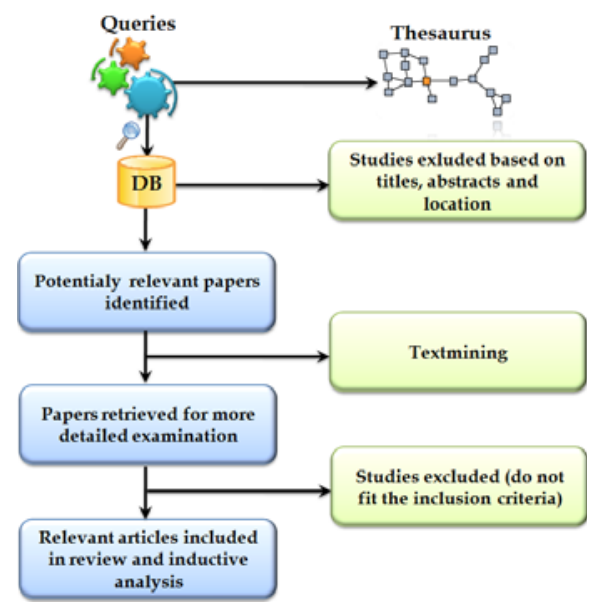

Fig. 1. Systematic review process

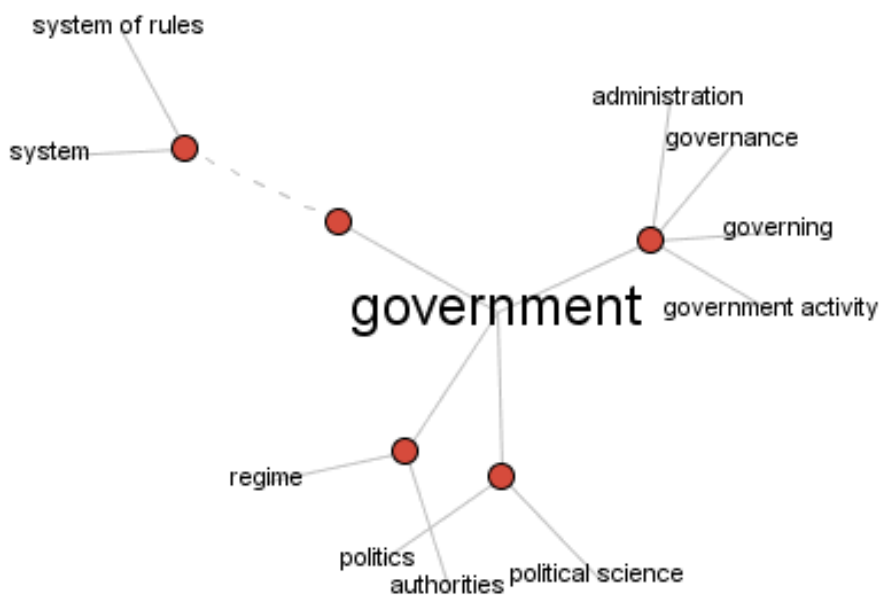

Fig. 2. Thesaurus of government concepts

More than one thousand papers were retrieved from the six databases. This number made it difficult to go through all of the selected papers. Hence, we used text-mining techniques in order to eliminate irrelevant ones. A paper was considered irrelevant if it contained a keyword less than five times. These techniques reduced the final number of papers to eight hundred. 


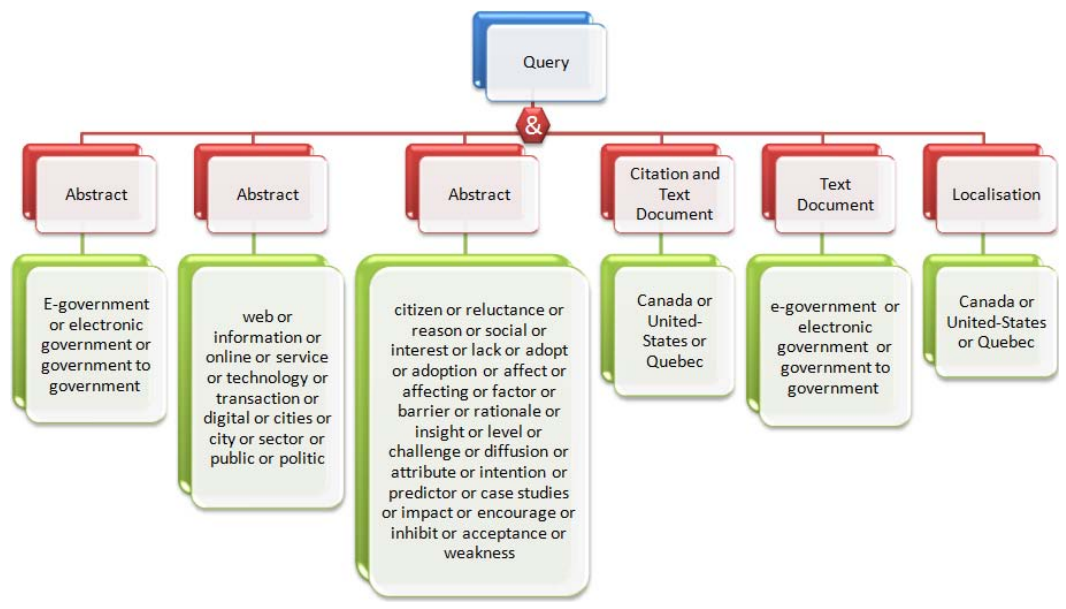

Fig. 3. Example of a query used to search articles on the topic of G2G

Finally, the third stage was to apply the selection criteria to the eight hundred papers in order to select those that were related to the subject at hand. The selection criteria encompassed inclusion and exclusion criteria. The inclusion criteria were:

- The paper should include definitions of services available electronically, as well as definitions of G2G procedures, policies, and stakeholders.

- The paper should describe relationships between government agencies.

- The paper should describe the factors that influence governance relationships between government agencies.

- The paper must explore the dimensions associated with various factors that enhance relationships between government agencies.

- The paper should address strategies and the best ways to improve G2G service delivery.

We rejected papers on government-to-citizen (G2C) and government-tobusiness (G2B) relationships. Furthermore, we decided to study only papers from developed countries, since those countries have the most G2G-related papers. Finally, we rejected papers on e-election, e-democracy, and the social impact of e-government.

Table 1. Results of selection of studies

\begin{tabular}{|c|c|c|l|}
\hline Database & Number of shown studies & Number of selected papers & Number of excluded papers \\
\hline PROQUEST & 137 & 47 & 90 \\
\hline EBESCO & 149 & 15 & 134 \\
\hline ISI Web of Science & 177 & 33 & 144 \\
\hline Science Direct & 149 & 1 & 138 \\
\hline Social Science & 65 & 4 & 61 \\
\hline GPO Access & 123 & 2 & 121 \\
\hline Total & 800 & 112 & 688 \\
\hline
\end{tabular}


Table 1 summarizes the results from this literature review for the number of found, selected, and rejected papers. Out of the 800 papers, only 112 were selected and 688 were rejected.

\section{$3 \quad$ ICT and Organizational Factors}

This section presents an analysis of the different selected papers. Due to limited space, we cannot present all of them. Only the ones mainly used to develop the conceptual model are referred to in this paper.

Successful G2G requires implementing more rational management and collaboration policies, more reliable strategies, and sustainable investments. G2G has gone through two phases of growth or change: catalogue access and transaction capability [18]. Catalogue access provides government agencies with information-sharing infrastructure, e.g., via intranets. Transaction capability provides government agencies with means to exchange data and manage transactions in real time.

Several studies have identified the factors that impact G2G relationships. The factors are mainly related either to information and communication technologies (ICT) or to organizational aspects. Some studies focus only on ICT factors, others on organizational factors, and others still on both.

\subsection{Studies That Focused Only on ICT Factors}

In this subsection, we present the works of McKinnon, Morgeson and Mathias, and Moon. 14] has studied relationships between government agencies as an exchange of data between these agencies. Electronic data can be exchanged if the computing systems use the same data format. The agencies should thus adopt and disseminate a common format. Government agencies should ensure secure exchange of data 14. Security makes it easier to create and develop an efficient G2G system 14.

Furthermore, as in [14, 17] identified factors relating to information and communication technologies. These factors are the adoption of information technology, the creation of a strong technological infrastructure, and the development of G2G Information Systems. Improving G2G services requires adopting new information and communication technologies within government agencies. Specifically, the ICTs should make the following possible: orchestrate and integrate IT services within government agencies; strengthen communication between government agencies; adopt effective strategies and best practices for improving the web sites of government agencies; and finally adopt business information systems and service-oriented architecture (SOA) to organize and orchestrate government agencies' services.

Finally, in [16], four major ICT factors can impact relationships between government agencies: (1) establishment of a secure government Intranet and a central shared database to enhance cooperation, collaboration, and interaction between government agencies, (2) delivery of online services, (3) more effective application of e-commerce in transaction activities between government agencies, and (4) transparency in governance. 


\subsection{Studies That Focused Only on Organizational Factors}

In this subsection, we present the works of Streib and Navarro, Tat-Kri Ho, and Tolbert et al. 23. studied and analysed the factors that affect G2G development. They found that development depends on the creation of organizational strategies. To this end, they proposed two organizational strategies: effective governance strategy to ensure control of both information flow and information sharing, and effective management strategy of operations in government agencies. These strategies can be supported by ICTs and can help develop G2G applications in government agencies, build G2G infrastructures, remove bureaucratic obstacles for the purpose of transforming G2G architecture, and satisfy the business requirements of different organizations included in the G2G.

G2G growth depends on the organizational structure of government processes and human resources management [7. For 24] delivery of a public service requires coordination between the service centre and a one-stop single window with functional departments, such as local police and planning or transportation officials. Several dimensions can affect development of a strategic G2G vision: inadequate staffing; lack of funding and lack of staff for online service development and maintenance; the digital divide between racial groups; resources for technological changes in an organization; operations carried out by ministries; social concerns; economic disparities; and racial disparities in the digital age.

Finally, 27] identified dimensions related to human resources management that can impact G2G relationships. These dimensions are institutional capacity building, slack resources, and environment of innovation policies associated with human resources management for the G2G. Institutional capacity is defined as the technology implemented to facilitate organizational changes through the flattening of hierarchies, decentralization, and new reforms. Slack resources are defined as government income per capita with respect to degree of investment in technical and administrative infrastructure.

\subsection{Studies That Focused on Both ICT and Organizational Factors}

In this subsection, we present the works of Siau et al., Reddick, Kung et al., and Coursey et al. The first model is by [22]. This model uses ICT factors and level of human development factors. ICT factors are government information, government services, and computer science technologies. Government information refers to data stored in different formats such as hard-copy documents, electronic documents, electronic spreadsheets, databases, and knowledge. Government services are online facilities provided by government Web sites. Computer science technologies are telecommunication infrastructures. The factors associated with level of human development are longevity (as measured by life expectancy at birth), knowledge (as measured by combining the adult literacy rate and enrolment rates at primary, secondary, and tertiary levels of education), and finally living conditions (as measured by GDP per capita). Therefore, 'the higher the level of information technology and human development, the more advanced is egovernment development' ([22]). 21] recommend considering additional factors 
(culture, government policies, and leadership) that can influence governance relationships.

18 states that the governance model has an impact on the degree of cooperation between government agencies. It can be influenced by factors grouped into three categories: (1) external influences (requests from citizens for online services) (26]), (2) key characteristics of e-government (e.g., efforts by government agencies to reduce their administrative costs), and (3) organizational factors that enhance growth (e.g., creation of separate IT departments) 9]. Furthermore, in another study, 19 focused on other key factors that affect the perceived effectiveness and performance of G2G relationships. These factors are the management capacity of the administration, security and confidentiality, and collaboration (demand for intergovernmental, interagency, and inter-sector developments) 11. Each factor has several elements. The management capacity elements are content, leadership, strategic planning, and collaboration. The security and confidentiality elements are information security, IT administrators, and organizational factors. Finally, the collaboration elements are expressed through information sharing between different government levels [8].

In [12], G2G relationships succeed because of three main elements: the government works to upgrade the skills of professionals in new ICTs to improve G2G application quality, the government agencies take into account both their IT infrastructure and the development of their human resources, and finally the government agencies ensure that their online services are delivered to citizens securely. To meet these constraints, several factors must be addressed. These factors are grouped into a theoretical model [12]: (1) technology (2) information security, (3) development of business processes, (4) project management, (5) communication, (6) lawyers, and (7) human resources.

Finally, 6] focused on the governance factors that can impact G2G relationships. These factors are interactivity, interactions, integration, and information provision. Interactivity represents the ability of citizens to interact and contact governmental agencies. Transaction is defined by [29] as the exchange of value between two entities (an entity can be either a government agency or a citizen). Integration is of two types: vertical integration and horizontal integration. Vertical integration is the sharing of information between government agencies of different levels (e.g., municipal, provincial, and federal). Horizontal integration is the sharing of information between government agencies of a single ministry. Finally, information provision or cataloguing allows governments to move toward a transactional stage 13 .

From these different studies, several factors have been identified. In the next section, we will provide a conceptual model that encompasses all of these factors and their relationships.

\section{Design of a Conceptual Model of Factors That Influence the G2G Governance Relationship}

The proposed conceptual model is developed using a general inductive approach 25] with the following objectives: (1) summarize the raw data, (2) determine 
the categories for analysis of raw data with reference to research objectives and finally (3) develop a model that organizes the links between different categories. An inductive approach was chosen because there is no limit to our knowledge of a comprehensive taxonomy of factors that affect the governance relationship between government agencies. The inductive approach is guided by the research aims and allows us to analyze the data and knowledge in scientific papers, to develop a codification process for data reduction, and to encode the data in a comprehensive framework to identify, organize, and classify the potential factors that influence the governance relationship between government agencies.

The big challenge is to ensure that the identified categories of factors share the following characteristics that have been defined with respect to the recommendations of [25]:

- gives each category a label or a text segment (word, term or phrase).

- describes the meaning of each category by defining its key features and scope and delimitation (delineation) of its borders.

- associates a detailed description with each category extracted from selected scientific papers and studies, including portions of text, quotes, and images.

- establishes links between the different categories.

- and develops a conceptual model that describes the network of the identified categories.

Referring to the various recommendations proposed by [25], we undertook a process of consolidation to create well-defined categories of the identified factors. First, we identified several sets of text segments that have a unique meaning. At this level we assigned labels to each unit of meaning to describe new categories. After identifying different categories, we gave them initial definitions.

At this stage, we reviewed the categories we identified to eliminate redundant ones and to refine them. Furthermore, we identified sub-categories and their links to establish networks of concepts that represent the end point of the analysis. Then, we went through the different papers a second time in order to identify the links between the different categories from the previous stage. The theoretical model after revision and refinement of the categories of factors is shown in Figure 4

The proposed model has 26 categories. It is organized as follows. First, coordination involves three subcategories: local coordination, regional coordination, and national coordination. In general, coordination is supported by a collaborative process between government agencies that depends on new information and communication technologies. At this level, ministries and government agencies make some investments to implement digital infrastructure through information and communication technologies. The ICTs provide fast and reliable access to information sources and government services. In addition, they facilitate information sharing and enhance security and confidentiality. Also, the governance relationship between $\mathrm{G} 2 \mathrm{G}$ agencies depends: first on effective deployment of information and communication technologies and institutional capacity; second on legislation that regulates the governance structure; and third on institutional 


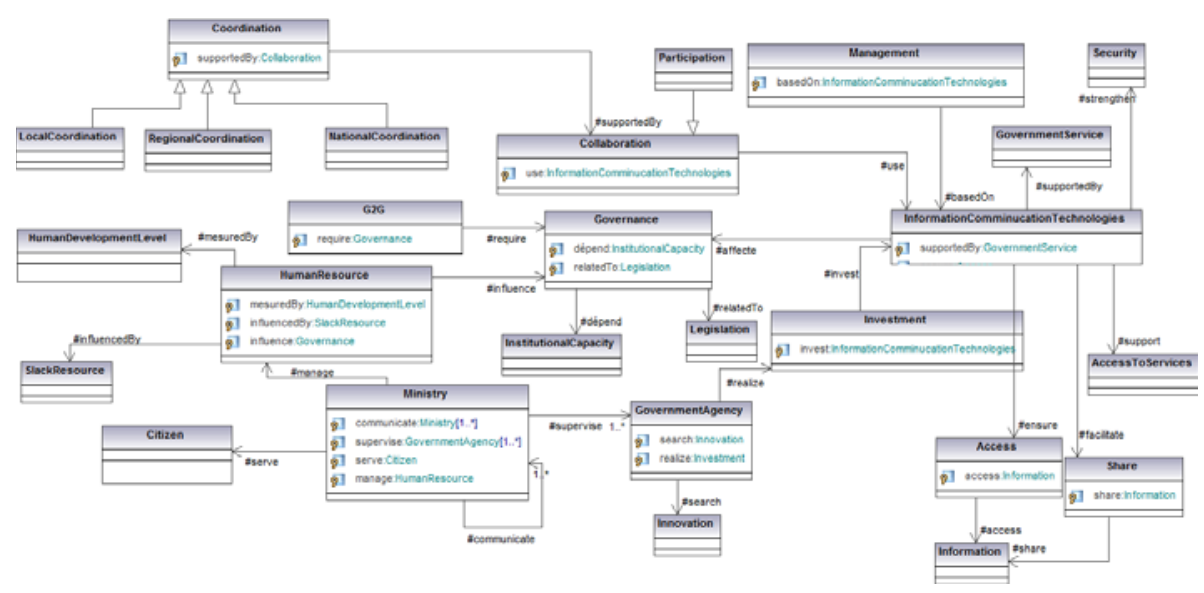

Fig. 4. Conceptual model of factors that influence the G2G governance relationship

capacity to operate with other government agencies. Each ministry serves citizens and manages human resources. Human resources are influenced by slack resources and measured by human development level.

\section{Conclusion}

G2G consists of electronically supported ICT activities between the business units of government, including those within the same governmental body. For many of these activities, the aim is to harmonize procedures, and to improve the effectiveness or efficiency of government [28]. Moreover, we can say that G2G primarily involves the use of ICT among various government agencies to increase effectiveness and efficiency of available services. G2G is a prerequisite for other e-government services, such as G2C and G2B.

This study had two objectives. The first one was to identify and classify the factors that influence the governance relationship between the central government and its regional agencies. The second one was to develop a conceptual framework in order to describe and understand this governance relationship. Thus, our research project used general inductive analysis to develop a general conceptual model of factors that influence the governance relationship between the central government and its regional governmental agencies.

As a future avenue of research, we wish to investigate the classes of factors identified by this study. We aim to develop a methodology based on the work of [20], which focuses on assessing factors that influence the alignment of business and information technology. Thus, the first stage is to develop questionnaires. The second one is to interview a number of actors from the central government and its regional agencies and take notes. The third one is to develop a relationship site. The last one is to examine each factors relationship separately to assess 
its influence on the governance relationship. An additional avenue for research would be to identify ways to overcome the socio-technological barriers to the penetration of $\mathrm{G} 2 \mathrm{G}$ in outlying regions.

\section{References}

1. Smith, T.F., Waterman, M.S.: Identification of Common Molecular Subsequences. J. Mol. Biol. 147, 195-197 (1981)

2. National Center for Biotechnology Information, http://www.ncbi.nlm.nih.gov

3. Becheikh, N., Landry, R., Amara, N.: Lessons from innovation empirical studies in the manufacturing sector: A systematic review of the literature from 1993-2003, vol. 26(5-6), pp. 644-664 (May-June 2006)

4. Chourabi, H., Mellouli, S., Bouslama, F.: Modeling E-Government Business Processes: New Approaches to Transparent and Efficient Performance. Journal of Information Polity 14(1-2) (2009)

5. Jadad, A.R., Cook, D.J., Browman, G.P.: A guide to interpreting discordant systematic reviews. Canadian Medical Association Journal 156(10), 1411-1416 (1997)

6. Coursey, D., Norris, D.F.: Models of E-Government: Are They Correct? An Empirical Assessment, vol. 68(3), pp. 14-523 (2008)

7. Damanpour, F., et Evan, W.M.: Organizational innovation and performance: the problem of organizational lag. Administrative Science Quarterly 29, 392-409 (1984)

8. Gil-Garcia, J.R., Chengalur-Smith, I., Duchessi, P.: Collaborative e-Government: impediments and benefits of information-sharing projects in the public sector. European Journal of Information Systems 16, 121-133 (2007)

9. Holden, S., Norris, D., Fletcher, P.: Electronic Government at the Local Level: Progress to Date and Future Issues. Public Performance and Management Review 26(4), 325-344 (2003)

10. Kavadias, G., Tambouris, E.: GovML: a markup language for describing public services and life events. In: Wimmer, M.A. (ed.) KMGov 2003. LNCS (LNAI), vol. 2645, pp. 106-115. Springer, Heidelberg (2003)

11. Kim, H.J., Lee, J., Kim, S.: Linking Local E-Government Development Stages to Collaboration Strategy. International Journal of Electronic Government Research 4(3) (2008)

12. Kung, H.-L., Tung, H.-L., Case, T.: Managing E-Government Application Evolution: A State Government Case. International Journal of Cases on Electronic Commerce 3(2), 18-36 (2007)

13. Layne, K., Lee, J.: Developing fully function e-government: A four stage model. Government Information Quarterly 18(1), 122-136 (2001)

14. McKinnon, C.: Challenges Facing the Public Sector. KM World: Jun 2005 14(6), S3-S4 (2005)

15. Mellouli, S., Bousalam, F.: Intelligent Agents for E-Government Development. Electronic Government, An International Journal 6(2), 177-192 (2009)

16. Moon, M.J.: The evolution of E-government among municipalities: Rhetoric or reality? Public Administration Review, Washington, vol. 62(4), pp. 10-424 (July/August 2002)

17. Morgeson, F.V., Mithas, S.: Does E-Government Measure Up to E-Business? Comparing End User Perceptions of U.S. Federal Government and E-Business Web Sites, vol. 69(4), pp. 13-740. Public Administration Review, Washington (2009) 
18. Reddick, C.G.: A two-stage model of e-government growth: Theories and empirical evidence for US cities. Government Information Qauterly 21(1), 51-64 (2004)

19. Reddick, C.G.: Factors that Explain the Perceived Effectiveness of E-Government: A Survey of United States City Government Information Technology Directors. International Journal of Electronic Government Research 5(2), 1-15 (2009)

20. Reich, B.H., Benbasat, I.: Factors that influence the social dimension of alignment between business and information technology objectives. MISQ 24(1) (2000)

21. Siau, K., Long, Y.: Using social development lenses to understand e-government development. Journal of Global Information Management 4(1), 47-62 (2006)

22. Siau, K., Long, L.: Factors impacting E-government development. The Journal of Computer Information Systems 50(1), 10-98 (2009)

23. Streib, G., Navarro, I.: City Managers and E-Government Development: Assessing Technology Literacy and Leadership Needs. International Journal of Electronic Government Research 4(4), 17-37 (2008)

24. Tat-Kei Ho, A.: Reinventing local governments and the E-government initiative. Public Administration Review, Washington 62(4), 434-444 (2002)

25. Thomas, D.R.: A general inductive approach for analyzing qualitative evaluation data. American Journal of Evaluation 27(2), 237-246 (2006)

26. Thomas, J.C., Streib, G.: The New Face of Government: Citizen-Initiated Contacts in the Era of E-Government. Journal of Public Administration Research and Theory, Vol 13(1), 83-102 (2003)

27. Tolbert, C.J., Mossberger, K., McNeal, R.: Institutions, Policy Innovation, and EGovernment in the American States, vol. 68(3), pp. 15-549. Public Administration Review, Washington (2008)

28. Turban, E., Lee, J.K., et al.: Electronic Commerce 2010. 6/E Prentice Hall, Englewood Cliffs (2010)

29. Wescott, C.G.: E-Government in the Asia-pacific region. Asian Journal of Political Science 9(2), 1-24 (2001) 